Portland State University

PDXScholar

\title{
Life Near Death: The Impact of Support Groups for People with Terminal Cancer on Preparatory Grief
}

Ariel Young

Portland State University

Follow this and additional works at: https://pdxscholar.library.pdx.edu/honorstheses

Let us know how access to this document benefits you.

\section{Recommended Citation}

Young, Ariel, "Life Near Death: The Impact of Support Groups for People with Terminal Cancer on Preparatory Grief" (2014). University Honors Theses. Paper 78.

https://doi.org/10.15760/honors.63

This Thesis is brought to you for free and open access. It has been accepted for inclusion in University Honors Theses by an authorized administrator of PDXScholar. Please contact us if we can make this document more accessible: pdxscholar@pdx.edu. 


\section{Life near death:}

The impact of support groups for people with terminal cancer on preparatory grief

by

Ariel Young

An undergraduate honors thesis submitted in partial fulfillment of the requirements for the degree of

Bachelor of Arts

in

University Honors

and

Psychology

Thesis Adviser

Dr. Tina Burdsall

Portland State University

2014 


\begin{abstract}
Growing evidence suggests that preparedness for death can lead to positive outcomes for the dying and for the bereaved. Preparatory grief, grieving one's own death before it occurs, is grossly understudied. More research is necessary in order to understand the needs of the dying and to design more effective support systems to meet those needs. Within the next few decades a significant increase in the number of individual's living with long-term terminal illness and in need of end-oflife care is virtually inevitable. Current support systems may be outdated and thus inappropriate for these individuals.

This thesis reviews relevant literature regarding death, dying, loss, bereavement, preparatory grief, anticipatory grief, and existing social support for people diagnosed with terminal cancer. The research presented lays the foundation for a study intending to measure the impact of current support groups for people with terminal cancer on preparatory grief. Mystakidou's Preparatory Grief in Advanced Cancer Patients (PGAC) scale could be used to record a baseline of preparatory grief in people diagnosed with terminal cancer before they have sought any kind of support and then used again to longitudinally measure preparatory grief over time.
\end{abstract}




\section{Table of Contents}

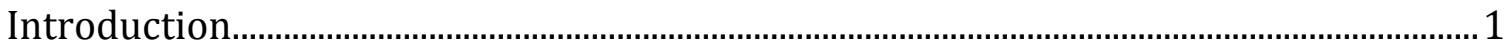

The changing faces of death and dying ....................................................................... 2

Advanced cancer and psychological care ................................................................... 5

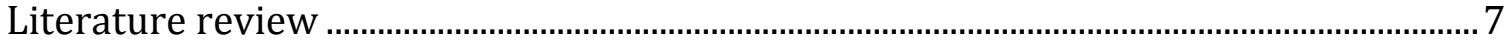

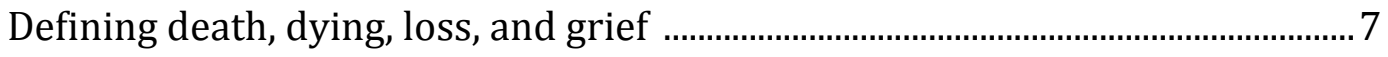

Beyond grief: Bereavement, anticipatory, and preparatory grief ...................... 12

Preparatory grief and clinical depression .................................................................. 15

Support groups for people with advanced cancer .................................................. 17

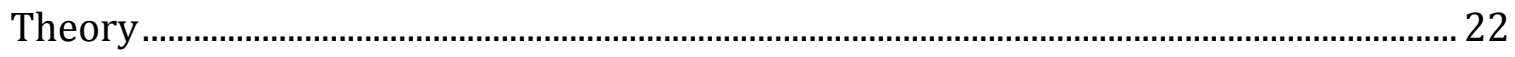

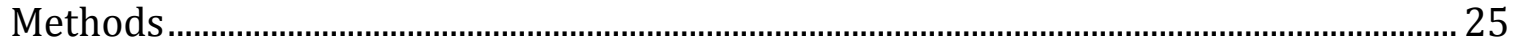

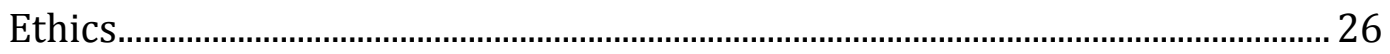

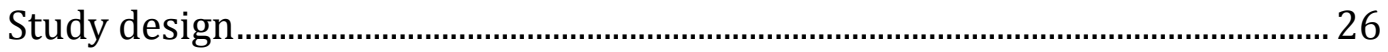

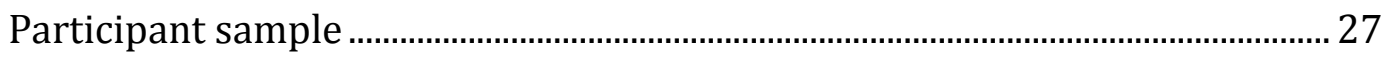

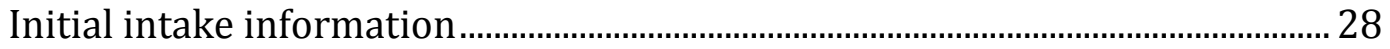

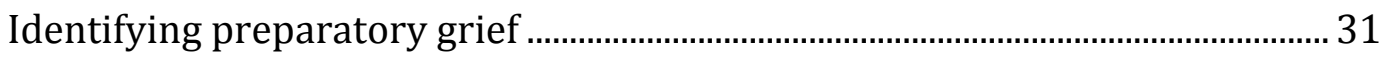

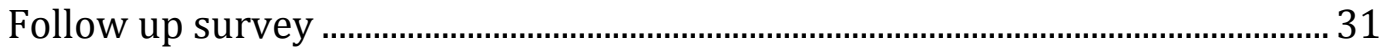

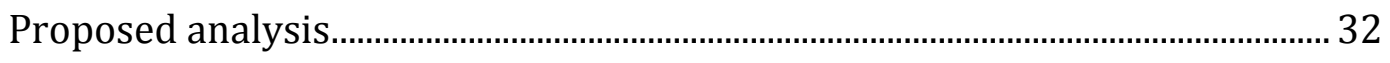

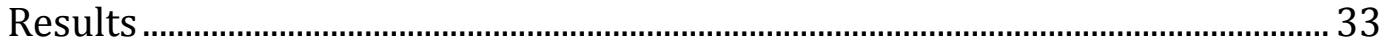

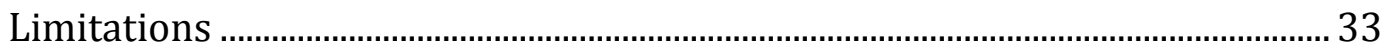

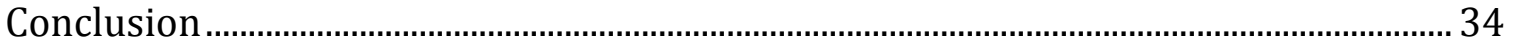

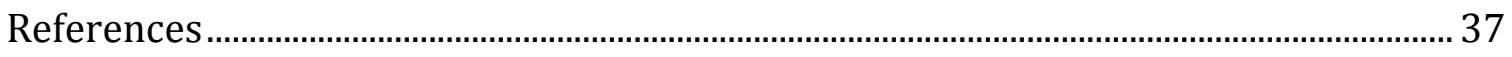




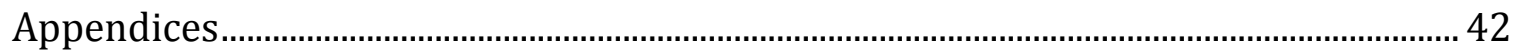

Appendix A: Informed consent form ........................................................................... 42

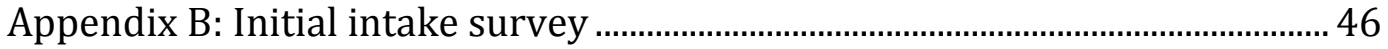

Appendix C: Preparatory Grief in Advanced Cancer (PGAC) patients

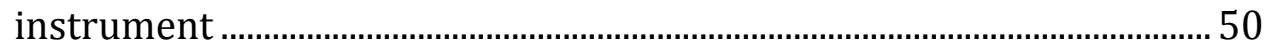

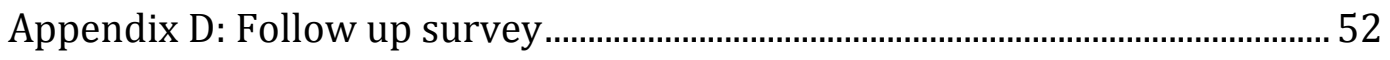




\section{Introduction}

Mark Twain once said "The fear of death follows from the fear of life. A man who lives fully is prepared to die at any time." While it is ambitious indeed to aspire to be ready for death at any given moment, research from the last two decades indicates that programs designed to provide psychological support to people diagnosed with cancer can have positive outcomes for the dying and also for the bereaved. The purpose of this thesis is to propose research that would assess the impact of existing support groups for people with terminal cancer on preparatory grief.

There are three major components of grieving the loss of life: anticipatory grief, bereavement, and preparatory grief. Anticipatory grief is grieving the death of a loved one before they die and is the predecessor for bereavement (Evans, 1994). Preparatory grief is the process of grieving one's own death before it occurs and it is perhaps the least studied aspect of death and dying (Mystakidou, Tsilika, Parpa, Katsoua, Sakkas, \& Soldatos, 2005). It is distinct from bereavement, the process of grieving the death and loss of a loved one and the most widely recognized form of grief, because it occurs before a person dies and is experienced by that person rather than by their family and friends. While each of these constructs are undeniably distinct, they bear resemblance to one another in terms of psychological experience and etiology. 
Overall, preparatory grief has been neglected by scholars and researchers until only recently. "Grief work," a term for processing and accepting loss, was for some time the exclusive domain of those who had survived death. Now the term is being more broadly applied to different kinds of grief, which has expanded the perspective of death and dying. While this field of study is growing, many still shy away from these topics. The need for research on preparatory grief has never been greater.

The changing faces of death and dying

Improvements in medical technology are constantly extending life and thus prolonging dying. Life-saving interventions run the gamut from the Heimlich Maneuver and CPR to chemotherapy and highly sophisticated pharmaceuticals. The advent of 3D printers allows surgeons to print out a realistic copy of an organ to practice on before operating, increasing the chance of the patient's survival. Techniques are becoming more advanced and sophisticated and the human life expectancy in the United States has never been higher.

How people come to die has changed dramatically over the course of the last century, with fewer people dying of more treatable ailments like pneumonia and more people dying of chronic terminal illnesses like cancer and organ failure (Beauchamp \& Veatch, 1996). Joanne Lynn writes "the great success of modern medicine has been to transform acute causes of death into chronic illnesses" (Lynn, 2005, p. S14). One of the unintended consequences of advancements in medical 
technology is the medicalization and institutionalization of death. One study in England and Wales found that four times as many people died in institutions-such as hospitals, hospice, communal homes, and psychiatric wards-than in a home (Gomes \& Higginson, 2008).

Lynn identifies three main trajectories of decline which have emerged as a result of improved medical technology. The first is "long maintenance of good function despite known fatal illness" (Lynn, 2005, p. S16). After an extended period of acceptable if slightly decreased function, this trajectory declines rapidly over the course of a few weeks or months, at which point the illness eventually becomes overwhelming and ends in death. Roughly twenty percent of Americans follow this trajectory, which is the most common trajectory for cancer. The second is "slow decline in physical capacities punctuated by serious exacerbations, with death often coming rather suddenly," a course seen often in cases of organ failure (Lynn, 2005, p. S16). Roughly twenty five percent of Americans follow this trajectory. Finally, the third trajectory is "long-term dwindling of function, needing years of personal care" and approximately forty percent of Americans follow this course (Lynn, 2005, p. S16).

Imminent changes in the United States' population within the next few decades only deepens the need for improvement in end-of-life care, particularly for those diagnosed with long-term illnesses such as cancer. Within the span of only a few decades at the very most, the number of Americans in need of end-of-life care such as hospice is expected to increase by several percents (United Nations, 
Department of Economic and Social Affairs, World Population Prospects: The 2012 Revision, n.d.). More than half of Americans already use hospice care at least briefly over their lifespans (Lynn, 2005) and many more are predicted to follow due to an aging population and their increased risk of long-term, fatal illnesses.

In 2012, the American Cancer Society predicted that 1,638,910 new cases of cancers would be diagnosed in America (American Cancer Society, Cancer Facts and Figures, n.d.). This figure includes all cancers except non-invasive cancers of the bladder, and basal and squamous cell skin cancers, which are not required to be reported to cancer registries. More than half a million Americans die of cancer each year, which averages to more than 1,500 people a day. One in four Americans die of cancer, making cancer the second leading cause of death in America, exceeded only by heart disease (American Cancer Society, Cancer Facts and Figures, n.d.). These figures point to the need to study cancer, particularly from the standpoint of end-oflife care.

The preponderance of psychological research which studies people with terminal illnesses has focused on cancer. This is likely because cancer is a rising cause of death in the Western world and if predictions are to be trusted, the rates will only continue to rise. The best available tool for measuring preparatory grief, the Preparatory Grief in Advanced Cancer (PGAC) patients instrument, developed by Mystakidou et al. (2005), is as its title suggests designed for people with advanced cancer. For these reasons, this research also focuses on people with terminal cancer. 
Advanced cancer and psychological care

Changing causes of death and trajectories of decline are a direct result of improved medical technology. As medicine continues to advance it is to be expected that people will live longer and healthier lives. However, the changes these advancements bring about in the dying process cannot be ignored. End-of-life care must continue to evolve to reflect developments in medicine. Part of this change must include psychological care that is designed for people with chronic and eventually fatal illnesses like cancer.

Research has found that symptoms related to existential concerns and psychological distress are more prevalent in people with advanced cancer than physical pain and other physical symptoms (Breibart, 2002). Rates of anxiety and depression are sometimes difficult to estimate in people with terminal cancer due to resemblances in symptoms between these psychological disorders and the side effects of being treated for cancer, such as fatigue, loss of appetite, and changes in sleep patterns. However, reported rates of these psychological disorders among people with terminal cancer can range as high as $49 \%$, and in some cases $75 \%$ (Nordin, Berglund, Glimelius, \& Sjödén, 2001). Compared to a roughly 6.7\% rate of depression and $18.1 \%$ rate of anxiety in the United States population aged 18 and older (National Institute of Mental Health, The Numbers Count: Mental Disorders in America, n.d.), people with terminal cancer have alarmingly high rates of these disorders. This research points to the need for psychological intervention in end-oflife care for people with terminal cancer. 
There has been a considerable amount of research regarding the positive impact of support groups for people with cancer, including advanced, metastasized, and terminal cancers. Support groups are an efficient psychological intervention in terms of time and money, and have been shown to improve overall quality of life across physical, psychological, and spiritual domains (Breibart, 2002). Some research has found that support groups can reduce traumatic stress after a diagnosis of terminal cancer (Classen et al., 2001). Spiegel, a major player in psychological care for people with cancer, found that support groups have the power to reduce anxiety, depression, and hopelessness (Spiegel \& Yalom, 1978).

To date, no formal research has been conducted on the impact of support groups for people with terminal cancer on preparatory grief. Anxiety, depression, and hopelessness may be a part of preparatory grief for some individuals, as well as existential concerns. However, preparatory grief encompasses a broader range of experience which may not fall into the psychopathological range. This lens allows for a more holistic approach to psychological intervention in end-of-life care, which will ultimately lead to better outcomes for not only people with terminal cancer but all people who seek end-of-life care. 


\section{Literature review}

Defining death, dying, loss, and grief

There is much discussion and disagreement regarding the definition or definitions of death. Perhaps the most common and widely accepted definition is known as "whole death," which is the irreversible cessation of circulatory and brain functions (Beauchamp \& Veatch, 1996, p. 12). This definition is accepted across a variety of disciplines and cultures because it is largely indisputable. However, advances in medical technology, such as artificial respirators which allow a person to breathe without activity in the portion of the brain which controls respiration, the brain stem, have changed what it means to be dead.

New definitions have emerged to better describe and explain the variety in meanings of death. In addition to whole death, there is "whole brain death", the irreversible cessation of detectable activity in all regions the brain (Lynn, 1983). However, the entire brain does not always cease activity at the same time. There are occasions when only certain regions die while others remain intact. "Brain stem death" is the irreversible cessation of detectable activity in the brain stem with continued function in the cerebellum (Lynn, 1983). A person who is brain steam "dead" may continue to "live" by means of life support technology. "Higher brain death" is functionally the opposite of brain stem death: it is the irreversible cessation of detectable activity in the cerebellum with continued function in the brain stem (Lynn, 1983). The term "brain dead" is often used interchangeably and 
without distinction to refer to any and all of the definitions of death that are determined by activity in the brain.

In 1981 the President's Commission issued the following definition: “An individual who has sustained either (1) irreversible cessation of circulatory and respiratory functions, or (2) irreversible cessation of all functions of the entire brain, including the brain stem, is dead" (Lynn, 1983, p. 264; Beauchamp \& Veatch, 1996, p. 6). This definition is useful because its flexibility allows for multiple conditions to constitute death, circumventing some of the difficulty in having a singular definition. This definition also succeeds in incorporating advancements in medical technology into the framework of language surrounding death and dying.

Defining death is serious not only because of the subject matter, but because of the definition's numerous implications. For example, how long should a person who has lost function and activity in their brain be sustained on life support? This could potentially shape grief and mourning for the bereaved. Furthermore, the definition of death also determines when organs, tissues, and other material can be removed from the body for donation. Knowing when it is permissible to treat a person's body as though it is dead is crucial for ethical, medical, and legal reasons.

Also worth considering is the idiosyncratic definitions of death that may arise from specific contexts. While the physiological definitions of death are fairly simple, death may come to mean many different things to different people. For example, an individual who is religious may see death as a transition from one kind of life to another, perhaps in a spiritual realm or in another being (DeSpelder \& 
Strickland, 1987). On the other hand, another person may see death as total annihilation (Schultz, 1978). In a support group for people diagnosed with terminal illnesses, allowing space for the participants to define for themselves what death means is an important element of person-centered care (Spiegel \& Yalom, 1995).

Person-centered care is an ideological approach to medical and psychological care which places the person experiencing symptoms and receiving treatment at the heart of care, serving as an alternative to the current ideology which objectifies and reduces people into patients (Ekman et al., 2011). The emphasis of person-centered care is the quality of life and well being of the person, as determined by them (Crandall \& White, 2007). Elements of person-centered care are: personhood, knowing the person, maximizing choice and autonomy, quality care, nurturing relationships, and a supportive physical and organizational environment (Crandall \& White, 2007). Howarth, Warne, and Haigh argue that part of person-centered care is recognizing and legitimizing the person's experience; "being believed and believing in" (2014, p. 346). The consistent and systematic application of personcentered care has already improved client satisfaction in long-term care facilities (Crandall \& White, 2007).

If death is difficult to clearly and concisely define, the definition of dying is even more elusive. When does one begin dying and how is it different from living? Some people consider dying to be a process of living (Stephenson, 1985), while others understand dying as the blurry middle ground between life and death. Much like the definition of death, the definition of dying is somewhat subjective. For 
example, when someone commences the dying process is often a matter of opinion. There are those who contend, somewhat pessimistically, that a person begins dying as soon as they are born. Within the context of preparatory grief, some regard the official diagnosis of an eventually fatal or terminal illness as the beginning of the dying process (Presberg \& Kibel, 1994). Still others argue that a person begins dying when they begin to show considerable signs of physical decline due to illness or age (Riley, 1983).

Facilitating space for a person diagnosed with a terminal illness to determine when they are dying has its merit. In a psychotherapeutic setting, part of personcentered care is using language that is determined not by the therapist or facilitator but instead by the client (Morgan \& Yoder, 2012). Other sources of information, such as members of the person's medical team, family, and friends, can be valuable to a discussion surrounding an individual's definition of dying. If a person is perhaps unwilling to accept the inevitability of death, these additional sources can provide a variety of perspectives.

Denial is so common an experience among the dying that Kübler-Ross, a widely recognized scholar and psychiatrist, dedicated the entire first stage of her model of grief and dying exclusively to denial. The complete cycle of stages in this model are as follows: denial, anger, bargaining, depression, and acceptance (Riley, 1983). Kübler-Ross' model is widely criticized for weak methodological practices. The five-stage model is not based on empirical research, but instead based on Kübler-Ross' anecdotal experience in working with the dying and bereaved 
(Pellegrino, 1970). The discrete and linear nature of the stages in this model is also a point of contention, as it does not reflect the broad variety in the experiences of dying. For example, a person may experience both denial and anger simultaneously or may vacillate between two or more stages. It is also worth noting that not all people experience all five of these stages of grief and dying. Despite its many objectors this model remains to be a popular understanding of dying.

Grief, according to James and Friedman, is "the most neglected and misunderstood experience, often by both the grievers and those around them" (1998, quoted in Flanagan-Kamisky, 2013, p. 71). Part of the lack of understanding of grief may be due to its complexity; grief is itself a broad term which encompasses a great many subcategories. Periyakoil, a forerunner in the field of preparatory grief research, understands grief as the "physical, psychological and cognitive changes that occur in response to an abrupt change in the relationship between the grieving person and the loss object" (Periyakoil \& Hallenbeck, 2002, p. 885). According to this definition, loss is a necessary component of grief.

The word loss is rooted in the proto-Germanic term lausa, meaning to "loosen, divide, cut apart, untie, separate" (Vromans, Schweitzer, \& Brough, 2012, p. 4). A person who is given a terminal diagnosis may experience some losses almost immediately, such as the loss of intrapersonal integrity, which includes autonomy and a sense of well being (Vromans, Schweitzer, \& Brough, 2012). Other losses over the course of terminal illness include loss of privacy, independence, dreams, dignity, money, control, interpersonal roles, and life itself (Mystakidou et al., 2005). There is 
evidence that the official notification of a terminal diagnosis can be so traumatictrauma here being defined as an uncontrollable and terrifying life event-that in addition to experiencing preparatory grief, a person may develop symptoms of posttraumatic stress (Presberg \& Kibel, 1994).

Beyond grief: Bereavement, anticipatory, and preparatory grief

Bereavement, or grieving the loss of someone who has died, is the most thoroughly studied aspect of grief, probably in part because it so much simpler and easier to study the living than the dying or dead. The word bereavement comes from a Germanic root word meaning shorn off or torn up, suggesting the sudden feeling of loss that often accompanies grief. Some research suggests that the most intense experience of bereavement after a death usually ranges from four to six weeks, with acute grief lasting several months, followed by an extended period of mourning (DeSpelder \& Strickland, 1987). The proximity of the individual who has died or the social significance of the relationship does not necessarily determine the severity of bereavement. The meaning and importance which the griever assigns to the lost person plays a greater role in the experience of loss (Stephenson, 1985).

Lindemann, whose essay on grief is considered classic, lists the following symptoms as common to individuals experiencing acute grief: a tight feeling in the throat, shortness of breath, sighing, an empty feeling in the abdomen, loss in muscular power, and intense emotional distress (1944). 
Anticipatory grief is experienced by some of the same people who experience bereavement, but before the death occurs. Evans defines anticipatory grief as "the reaction to the news of impending death and all that terminal illness may entail" (1994, p. 164). In the time between the diagnosis and the impending death, anticipatory grief allows a person to "rehearse" and imagine the oncoming loss of a loved one (Evans, 1994, p. 162), and grieve other losses such as health and happiness. Evans argues that this phenomenon should be instead known as "terminal response" (p. 159), as the word grief might suggest that the process of anticipatory grief mirrors the process of bereavement and too little research has been conducted on anticipatory grief to substantiate this claim.

Inadequate experimental design, and poor operational definitions and assessments of key terms and concepts contribute to the lack of consensus in literature and research regarding anticipatory grief. Some research suggests that anticipatory grief can have positive outcomes for the survivor, particularly in terms of adjustment after the death, although this may be dependent on the duration of the anticipatory grief period (Riley, 1983). Conversely, other research findings suggest that anticipatory grief may have negative outcomes. Riley found that the absence of tears and expressions of grief on the behalf of the survivors before death may cause the dying distress (1983). Thus, anticipatory grief may potentially unravel interpersonal bonds when they are desperately needed. More research is necessary to understand anticipatory grief. 
Preparatory grief often occurs simultaneously with anticipatory grief, as it is also a grief reaction that occurs in anticipation of an impending loss (Casarett, Kutner \& Abrahm, 2001; quoted in Tsilika, 2009) but is experienced instead by people who are dying or have been diagnosed with a terminal illness. Overall, preparatory grief is incompletely understood for the same reasons as anticipatory grief. Lack of an agreed-upon foundational language, inconsistent experimental design, and the methodological challenges inherent to studying people who are dying pose difficulties in conducting and drawing conclusions from research. Periyakoil and Hallenbeck define preparatory grief as "the normal grief reaction to perceived losses experienced by persons who are dying" (2002, p. 884). According to Kalish, preparatory grief is a multi-dimensional experience which occurs on three levels: the psychological, the interpersonal, and the socio-cultural (quoted in Mystakidou et al., 2005). The goal of preparatory grief is to prepare oneself for the final separation from life in this world (Tsilika et al., 2009).

The experience of preparatory grief is idiosyncratic and multiply determined. Rando emphasizes the role of physiological factors, such as overall health, pain, and fatigue, in preparatory grief (Tsilika et al., 2009). Mystakidou focuses on how feelings of hopelessness, anxiety, and depression relate to and predict preparatory grief (2008). Differences in personal meanings of death and dying which can be influenced by age, religious or philosophical beliefs, and cultural context, also shape how preparatory grief is experienced (Tsilika et al., 2009). 
Parkes and Weiss contend that preparation before death can be useful, but it may not be due entirely to preparatory grief itself but instead other psychosocial processes (Mystakidou et al., 2005). Levy argues that preparatory grief is in fact maladaptive as it is positively correlated with depression and anxiety, suggesting that it may be a risk factor for poor adjustment (Mystakidou et al., 2008). However, Parkes and Weiss found that when a person has been aided in expressing their grief over losses which occur early on in an illness, they are more likely to be able to cope effectively with the next loss (Mystakidou et al., 2005). For the dying, effective coping includes constructive emotional expression, managing physical symptoms, and maintaining realistic optimism about what remains of life (Spiegel \& Yalom, 1978). It seems that the management of preparatory grief is crucial for effective coping and healthy adjustment.

\section{Preparatory grief and clinical depression}

Depression and pain are the most common psychological issues among people diagnosed with terminal illness (Mystakidou, Parpa, Katsoua, Galanos, \& Vlahos, 2006). Between 22 and 75 percent of people diagnosed with terminal illness experience clinical depression (Periyakoil \& Hallenback, 2002). Clinical depression goes above and beyond the scope of normal sadness which occurs as a part of life. Naturally, sadness is an anticipated emotion after the diagnosis of a terminal illness, but since that sadness is culturally-sanctioned it is not considered psychopathological. 
The psychopathological disorder clinical depression is distinguished from sadness by its deviation from the established norm, its duration, and the dysfunction and distress it causes the individual (Periyakoil \& Hallenback, 2002). In the case of a person who is terminally ill, it can be particularly difficult to tell the difference between the normal physiological and psychological processes of dying and clinical depression. Symptoms of clinical depression such as depressed mood, significant weight loss or gain, changes in activity level and sleep patterns, and fatigue may also be interpreted as the poor management of physiological symptoms of a terminal illness, including the treatment of said illness (Periyakoil \& Hallenback, 2002). Symptoms of anhedonia, or the inability to feel pleasure, and suicidality separate preparatory grief from depression.

There are serious therapeutic implications of differentiating between clinical depression and preparatory grief. For instance, administering pharmaceutical therapy for depression to a person who does not in fact have depression inflicts all of the potential risks and side effects of the medication-including nausea, insomnia, and fatigue, which a person with terminal cancer already has a high risk of experiencing—with none of the benefits (Periyakoil \& Hallenback, 2002). However, allowing clinical depression to go untreated causes unnecessary suffering for the dying when they are already struggling. One study demonstrated that poor management of physical symptoms and psychological distress can radically increase a patient's desire for a hastened death (Mystakidou et al., 2006). 
Support groups for people with advanced cancer

Support groups for people with terminal illnesses have been shown to have positive effects on psychosocial adjustment, physical symptoms, and even survival rates (Classen et al., 2001). Spiegel writes, "The very message of joining a group at this time in a patient's life conveys the idea that the person has not been put out to pasture, that she is not without importance because she is dying, that what she does still matters" (1978, p. 243). Studies on support groups have found that participants of support groups have more hope and social skills, cope better with dying, and have a more internal locus of control, all of which improve quality of life (Presberg \& Kibel, 1994). A positive outlook on what remains of life is associated with fewer symptoms of distress, anxiety, hopelessness, and depression (Spiegel \& Yalom, 1978; Morgan \& Yoder, 2012; Presberg \& Kibel, 1994).

Most of the research conducted on support groups for people with terminal illnesses has been in groups for women with breast cancer, and sometimes homosexual men with human immunodeficiency virus. This may be due in part to the tremendous amount of funds allocated to the research of both these diseases. Women are also more likely to engage in psychotherapy than men (Crawford, 2012), making samples of women more accessible to researchers.

In the existing literature, two main approaches to support groups for people with terminal illnesses emerge: supportive-expressive and psychotherapeutic. Supportive-expressive support groups emphasize providing support and helping participants accept and cope with their disease-related stresses (Spiegel, 1995). 
Living with a terminal illness amplifies existential concerns about death, meaning, freedom, and isolation, and supportive-expressive support groups provide an arena in which participants can work through these concerns together (Spiegel, 1995). Psychotherapeutic support groups similarly emphasize emotional expression and social support, as well as facilitate cognitive symptom management skills (Spiegel, 1995). "Adaptive denial," a type of denial of mortality which allows for a person to reduce distress and thus theoretically function better, is encouraged in psychotherapeutic groups (Presberg \& Kibel, 1994, p. 23).

Options for support groups for people with cancer are as diverse as the people who seek them out. While some support groups are led by a mental health professional, others are taught by people who are either living with cancer or whose cancer is in remission, still others have no clear leader and are instead led by group members (Cancer.net, Support Groups, n.d.). There are a number of resources online, Cancer.org and Cancer.net being two of the most prominent, which can help direct people to support groups. These websites suggest that a considerable number of people are choosing to participate in group support online, in some cases in forums which are specific to a type of cancer.

Due to their private nature, it is difficult to precisely measure the number of people who are involved in support groups for people with cancer. Groups may be formal or informal, they may or may not take attendance. Although support groups for people with advanced and terminal cancers do exist, it is possible that a person with terminal cancer may not participate in one of these specific groups, opting 
instead to participate in a general cancer group, creating further difficulty in estimating the number of people with terminal cancer who use support groups. This lack of statistics points to a need for further research on support groups for people with cancer, particularly people with terminal cancer.

Support groups for people diagnosed with terminal illnesses have repeatedly been shown to improve the psychological, psychosocial, and physiological states, and overall quality of life of participants (Spiegel, 1995). Psychotherapies in general reduce anxiety and distress (Spiegel, 1995) and support groups enhance the members' sense of self-esteem and assertiveness (Spiegel \& Yalom, 1978). Assertiveness and emotional expression are related to higher rates of survival in people diagnosed with terminal illnesses (Presberg \& Kibel, 1994). Ventilating strong feelings, such as anger, regret, and shame, encourages other ways of healthy coping (Spiegel, 1995). In a study of supportive-expressive groups, participants involved in the support groups saw a significant decline in traumatic stress symptoms and mood disturbances when compared with participants in the control condition who did not attend a support group (Classen et al., 2001). Support groups provide opportunities for participants to learn powerful lessons about coping effectively with terminal illness. Group members may learn that they are more afraid of dying than they are of death itself (Spiegel \& Yalom, 1978). Spiegel notes that over the course of a breast cancer support group "the members came to feel less like passive victims of a disease process and more like experts on living" (Spiegel \& Yalom, 1978, p. 240). 
From fellow support group members, participants learn how to better cope with the physical symptoms of terminal illness and many see an overall reduction in physical symptoms (Spiegel, 1995). Managing the side effects of medical treatment is another topic often covered in support groups, particularly the side effects of cancer treatments such as chemotherapy and radiation, including nausea, pain, fatigue, and hair loss (Spiegel \& Yalom, 1978). These better coping habits may contribute to a longer survival time. In one study, every participant in the control condition who did not receive psychological interventions had died 48 months after the experiment began, while nearly one third of people in the treatment sample were still alive! (Spiegel, 1995)

Meaningful relationships formed in support groups may also contribute to the success of these groups. Friends and family may withdraw after a terminal diagnosis for any number of reasons: perhaps they are too uncomfortable to witness another person's physical decline, perhaps they are attempting to give the person who is dying plenty of space, perhaps they are waiting to be invited in, or perhaps they simply do not know what to say. In any case, isolation can be a dangerous, even deadly, environment for a person who is entering the dying process. Support groups provide the unique opportunity to be surrounded by other people who share similar terminal diagnoses. Many members of support groups discover an improved sense of interpersonal confidence and self-worth from sharing their knowledge and expertise with other members (Spiegel \& Yalom, 1978). Not only do high quality interpersonal relationships strengthen a person's psychological well-being, but can 
even mediate the immunological effects of acute and chronic stress (Presberg \& Kibel, 1994).

Witnessing the life and death of other group members may serve the purpose of detoxifying death for surviving group members, which makes accepting their own death as a part of the life cycle slightly less difficult (Spiegel \& Yalom, 1978). Members may find inspiration in the deaths of their friends and fellow members to live the remainder of their lives to the fullest.

Some support groups also provide members with the opportunity to consider the meaning of mortality and philosophize about the possibility of immortality. Wondering what happens, if anything, after death is a question most people ask over the course of their lives. Throughout history, individual human cultures have developed their own versions of immortality through afterlife and rebirth (DeSpelder \& Strickland, 1987). For some, biological immortality, the sense of living on through and in one's offspring and their offspring and so on, is comforting (Stephenson, 1985). Support groups are a place for people with terminal cancer to explore these possibilities with other people facing the same challenges.

With an agreed upon language to describe the experiences of grief and loss, more research on preparatory grief can be conducted including research which applies knowledge about preparatory grief to existing constructs such as support groups. The success of support groups at helping participants cope with the symptoms of their illnesses and their medical treatments, feelings of anxiety, depression, and hopelessness, and the isolation that often accompanies a terminal 
diagnosis has been well documented (Spiegel \& Yalom, 1978; Presberg \& Kibel, 1994; Lam et al., 2013; Murray \& Wright, 2012; Periyakoil \& Hallenback, 2002; etc.). However, no published research is available on the effect of support groups on preparatory grief. This thesis is an attempt to satisfy the growing need for preparatory grief support, including reviewing existing literature, creating a theoretical framework, and proposing research.

\section{Theory}

Positive psychology emphasizes goals, well-being, satisfaction, happiness, interpersonal skills, and perseverance, and is concerned with understanding what makes life worthwhile and aiding in self-direction and self-organization (Maddux, 2008). Positive psychology is the theoretical framework on which this research is built.

The illness ideology, also known as the medical model, pervades much of current psychology; the ubiquitous use of the term "mental illness" in the Diagnostic and Statistical Manual (DSM) serves as evidence of this disease-based approach. The use of the term "mental illness" within this model reflects the belief that psychological disorder is comparable to a biological disease when no such comparison is actually possible (Maddux, 2008). This choice in language focuses the attention of mental health care researchers, practitioners, and their clients on disorder, dysfunction, and disease, rather than strengths, aptitudes, and health. When the centerpiece of a psychological ideology is negative, there is a risk of 
obscuring the potential for healing, happiness, and wholeness. This illness ideology is problematic in its conception of psychological disorder and should not be applied to people who are experiencing preparatory grief.

Within the medical model, a psychological disorder or "mental illness" is considered to be a discrete entity contained within a sick individual who is seen as a patient by a doctor in order to treat or cure said illness (Maddux, 2008). Positive psychology challenges this assumption, arguing that mental health and psychological disorder are social constructs based on systems of cultural values, which thus cannot be proven either true or false. Maddux writes that current understandings of psychological disorder are "heuristic social artifacts that serve the same social and cultural goals as do our constructions of race, gender, social class, and sexual orientation, such as maintaining and expanding the power of certain individuals and institutions, and maintaining the social order as defined by those in power" (Maddux, 2008, p. 63).

Unfortunately, the illness ideology's conception of psychological disorder medicalizes and pathologizes normal reactions to extraordinary circumstances, such as the diagnosis of an eventually fatal disease, when these reactions may or may not be pathological. In the case of a person who has been diagnosed with terminal cancer, the experience of preparatory grief does not represent psychological disorder so much as an expected psychological response to the difficulty in accepting death. There are those who are justifiably concerned that the illness ideology will eventually pathologize almost every conceivable difficulty in the 
human lifespan. And this is where positive psychology serves as a beautiful alternative: Positive psychology staunchly rejects "the categorizing and pathologising of humans and human experience," in favor of promoting health, pleasure, happiness, and fulfillment (Maddux, 2008, p. 66).

It should be clarified that happiness cannot be the sole goal of end-of-life care. It would be ridiculous and unhelpful to attempt to delegitimize or erase the sadness most people with terminal illnesses experience. Wholeness, along with happiness, should be emphasized. Always being happy is an impossible goal that can only end in failure. Wholeness, on the other hand, includes happiness and sadness and is entirely more attainable. This is a more integrated perspective on the emotional well being of people with terminal illnesses.

There is utility in organizing and labeling symptoms into categories of disorder within the mental health industry in the United States. Access to services such as additional educational resources, pharmaceutical treatment, and other specialized programs is often contingent on a diagnosis of at least one psychological disorder. For example, a child with attention deficit hyperactive disorder may only be eligible for specialized education if he has been diagnosed by a clinician. Psychotherapy is often only billable to an insurance company when a diagnosis has been confirmed by a recognized practitioner. In some cases, giving a name or partial explanation to an experience may provide a client with some relief and may help them connect with a newfound community (Maddux, 2008). 
Preparatory grief is not yet and should not be considered a psychological disorder. It does not appear in the Diagnostic and Statistical Manual of Mental Disorders, it has no diagnostic criteria, and it has no prescribed treatment. Instead of conceiving preparatory grief as a problem or sickness which must be somehow be got rid of, positive psychology suggests that it should instead be thought of as normal reaction to an extraordinary circumstance. This allows for the focus of the person who has been diagnosed with a terminal illness, their medical team, and their community of family and friends to remain focused on goals, well-being, satisfaction, happiness, interpersonal skills, perseverance, talent, and wisdom (Maddux, 2008).

\section{Methods}

The following is a design proposal for a study which would measure the impact of support groups for people with terminal cancer on preparatory grief. Before this research can take place the initial intake form and the follow up survey must be validated. This would include tests for collinearity. In order to test for cognitive soundness, probing method cognitive interviews would be conducted. Any changes to either or both measures that arise from these tests would be made before they were administered to participants. 
Ethics

Whether or not people with terminal illnesses qualify as needing extended protections in research due to potentially increased physical, emotional, and psychological fragility as a result of serious illness is a subject of much contention. Koenig et al. argue that "it is ethical to ask dying patients to accept greater risk of participation" in qualitative study of end-of-life care because they are less likely to suffer any negative outcomes of "therapeutic misconception" (2003, p. S48). Fortunately, there is little personal risk involved in this experiment.

Preparatory grief has not yet been studied within the context of support groups for people with terminal cancer. That said, the benefits of support groups across physical, emotional, intra- and interpersonal, and spiritual domains have already been established (Breibart, 2002; Classen et al., 2001; Lam et al., 2013; Presberg \& Kibel, 1994; Spiegel, 1995; Spiegel \& Yalom, 1978). The evidence suggests that conducting a study in which participants are randomized into either a control group with no support group intervention or an experimental group with a support group intervention could potentially harm the participants, rendering the study's design unethical.

\section{Study Design}

This study is a non-equivalent control group, pre-test and post-test design, wherein "two groups which are similar, but which were not formed by random assignment, are measured both before and after one of the groups gets the program 
or experimental treatment" (Fitz-Gibbon \& Morris, 1987, p. 86). A non-equivalent control group design allows participants to self-determine which condition they would like to be in. Pre- and post-tests, in this experiment conducted with the Preparatory Grief in Advanced Cancer patients (PGAC) scale (Mystakidou et al., 2005), allow for comparisons to be made not only inter-condition populations but also intra-condition populations before and after an intervention, in this case a support group for people with terminal cancer. See Figure 1, adapted from How to Design a Program Evaluation (Fitz-Gibbon \& Morris, 1987, p. 86).

\section{Figure 1}

\begin{tabular}{|c|c|c|c|c|c|}
\cline { 2 - 6 } \multicolumn{1}{c|}{} & \multicolumn{5}{c|}{ Time } \\
\hline Condition & \multicolumn{2}{c|}{ Pre-test } & Intervention & \multicolumn{2}{c|}{ Post-test } \\
\hline Experimental & Intake survey & PGAC & $\begin{array}{l}\text { Formal cancer } \\
\text { support group }\end{array}$ & PGAC & Follow-up \\
\hline Control & Intake survey & PGAC & X & PGAC & Follow-up \\
\hline
\end{tabular}

Participant sample

This study requires a sample size between 200-400 people who have recently been diagnosed with a terminal cancer and who have not yet begun any kind of formal support program designed exclusively for people in this condition. This sample size reflects the sample sizes of psychological studies of people with 
terminal illnesses, including cancer. A larger sample size is advantageous when studying this population, as experimental mortality tends to be high among samples of people who are very sick. Excluding participants who have already begun a formal support program designed for people diagnosed with terminal cancer reduces the risk of contaminating the sample. Participants should be at least 18 years of age, fluent in English, and diagnosed with a terminal cancer. There are several layers of gatekeeping in acquiring a sample of such a vulnerable population, including the hospitals, oncologists and other members of medical teams, the families of potential participants, and the participants themselves. This sample could be most easily acquired by partnering with hospitals with a strong oncology program which are willing to work with researchers.

Initial intake survey

Demographic information should be collected after a participant has agreed to participate in the study and has given their informed consent. This information would include age, gender, race, level of education, marital status, number of household members, and income. These items are standard questions among surveys in psychological research. It would also be useful to collect information regarding participants' history of mental health. A history of psychological disorder such as anxiety or depression would be relevant to the study of preparatory grief, given the reported co-occurrence of these three constructs (Mytakidou et al., 2005; Tsilika et al., 2009; etc.). 
Information regarding the participants' cancers would also be relevant to the study. Questions on the intake survey would include the type of cancer, the time of the initial diagnosis, the time of the terminal diagnosis, and any treatments the participant has undergone, such as radiation, chemotherapy, surgery, and alternative medicine. Questions regarding a participant's physiological health are relevant because they can provide insight into later outcomes, and are often included in research conducted with people diagnosed with both terminal and nonterminal cancers (Lam et al., 2013; Boyes et al., 2009; Mystakidou et al., 2005; etc.). Reviewing the participants' charts may also provide this information.

The independent variable in this study is social support and identifying which kind or kinds of support a participant is interested in is the next step. This is where participants will self-determine whether they will be in the experimental or control condition. Participants in the experimental condition will participate in support groups for people with terminal cancer. For the purpose of this study, support groups are defined as groups of people with terminal cancer who periodically gather together either in person, online, or a hybrid of both to process their shared experiences. Support groups may be led by a mental health professional, a facilitator, a group member, or may have no formal leadership. These support groups may or may not have a religious or spiritual element.

Participants in the control condition will not participate in a support group for people with terminal cancer. This condition will include people who are receiving support but not in the form of a support group specifically for people with 
terminal cancer. The control condition includes: support groups which are not designed for people terminal cancer, individual counseling, general religious practice, community groups, and family and friends. It is also possible that participants may not be interested in structured social support. All of these participants are in the control condition because they are not in a support group specifically for people with terminal cancer. Of course, participants can change their mind about what condition they would like to be in. This may make statistical analysis more challenging, but it would be important and interesting to note who is changing conditions and why.

One of the potential outcomes of this initial intake survey is the discovery that the experimental and control participant populations are significantly dissimilar. For instance, there may be such a wide disparity in household income between participants who opt in to support groups and participants who opt out of support groups that the study could potentially be compromised. In order to avoid confounds, any significant dissimilarities between the control and experimental participants populations will be noted and controlled for in statistical analysis.

It is possible that a participant may not be able to fill out a follow up survey because they are either too sick or have already died. In order to reduce the impact of experimental mortality, each participant will be asked to identify a proxy, likely a family member, partner, or close friend, who has permission to respond in their place.

Please see Appendix B for the initial intake form. 
Identifying preparatory grief

Preparatory grief is the dependent variable in this study. To best assess the effect of support groups for people with terminal cancer on preparatory grief, participants' preparatory grief must be measured. In the context of this research, a positive effect on preparatory grief is defined as maximizing the possible benefits of preparatory grief, such as life-reflection, and personal and spiritual growth, while minimizing its risks, such as anxiety, depression, and hopelessness. Establishing a baseline before participants begin any sort of structured social support will allow for comparisons to be made between pre- and post-tests. The Preparatory Grief in Advanced Cancer patients (PGAC) instrument, developed by Mystakidou et al., is a validated tool which assesses a person's preparatory grief. This self-administered survey will be given to participants after they have signed the informed consent form and taken the initial intake survey.

Please see Appendix C for the PGAC instrument.

\section{Follow-up survey}

After the baseline for preparatory grief has been established, participants may or may not begin involvement in a support group designed for people with terminal cancer. In order to measure the effect of social support, such as a support group, some time must be allowed for the support to do its work. Ten weeks after the participant has filled out the initial intake form and the PGAC instrument, they will be asked take the PGAC instrument again. 
Participants will then be asked to fill out a short follow-up survey. This survey updates some of the information collected in the initial survey. Questions will include the treatments the participant has undergone, whether are not they are attending a support group, and what other kinds of support they may be receiving.

Please see Appendix D for the Follow-up survey.

In the event that a participant is unable to respond to the follow-up survey because they are either physically unable due to illness or because they have died, the proxy identified in the initial stage of the study will be asked to fill out the survey in their place. A new measure, separate from the measure listed above, which reports the proxy's perceptions of the participant's preparatory grief and successfulness of social support must be made in order to incorporate this additional source of information.

\section{Proposed analysis}

The aim of this research is to assess the independent effect of support groups for people with terminal cancer on preparatory grief. In order to address this question, pre- and post-test results using the PGAC measure will be analyzed. A 2panel analysis will be run to determine the effect of support groups on preparatory grief. Before the results of the PGAC measure are analyzed, variables such as type of cancer, age, race, gender, and income must first be weighted appropriately to avoid confounds. To provide a description of the effect of other variables such as race, 
class, gender, type of cancer, and type of cancer treatment on preparatory grief, a multivariate analysis will be explored.

\section{Results}

The results of this study would be quantitative data derived directly from the series of surveys, and possibly chart reviews. The measurements of preparatory grief as provided by the PGAC instrument both pre- and post-intervention will be assessed to determine the pattern of preparatory grief over time. Statistical analysis of the data would reveal correlations between participation in a support group for people with terminal cancer and preparatory grief, if any exist. If the results of studies on support groups' success discussed in the literature review are any indicator, it is reasonable to expect that the results of this study would suggest that support groups have a positive impact on group member's preparatory grief.

\section{Limitations}

There is methodological difficulty in studying people with terminal illnesses. One such difficulty is experimental mortality, when participants drop out of a study. In the case of people with terminal illnesses there is a heightened risk that participants may become too ill to continue to participate or die before the study has been completed. Larger sample sizes can help mitigate this challenge. Including responses from proxy participants, identified by primary participants during the initial intake phase, can also help reduce the impact of experimental mortality. 
Another limitation of the study is the impurity of the control condition. For the sake of simplicity, all participants who are not in a support group specifically designed for people with terminal cancer have been included in the control condition. A more sophisticated study would contain three conditions: an experimental condition composed of participants in support groups for people with terminal cancer, a second experimental condition composed of participants who have social support outside of support groups for people with terminal cancer, and a final control condition for participants who are not receiving social support. This design would allow for clearer results to be drawn from the research. However, the present design is not confounded by its conditions and still serves the important purpose of studying the impact of support groups for people with terminal cancer on preparatory grief.

\section{Conclusion}

Death is a universal fact of life; all people must eventually die. But that does not mean that the final years, months, weeks, days, and minutes leading up to death must be dreaded and lived in isolation. In fact, research suggests that sharing this process with other people makes dying less distressing, traumatic, and painful (Spiegel, 1995). The increasing rates of not only cancer and cancer deaths but long term illnesses as a whole demands attention to not only the affected people's bodies 
but also to their psyches. Providing quality end-of-life care to these people is a matter of fundamental human rights.

Support groups for people diagnosed with cancer are already providing support in the form of interpersonal connection and opportunities for intrapersonal growth (Presberg \& Kibel, 1994; Spiegel, 1995; Spiegel \& Yalom, 1978). These groups have been shown to reduce symptoms of cancer and cancer treatment, traumatic stress, anxiety, depression, and hopelessness (Presberg \& Kibel, 1994; Spiegel, 1995; Spiegel \& Yalom, 1978; Classen et al., 2001). Hopefully some day medical researchers will develop a cure or cures for cancer, reducing the need for such support groups. Until then, they remain a popular and effective psychosocial intervention.

Despite the considerable amount of research on support groups, no available research has been conducted on the impact of these groups on preparatory grief. While physiological status, traumatic stress, anxiety, depression, and hopelessness are incorporated into preparatory grief, preparatory grief also considers experiences which may not fall into the pathological range. Including the study of preparatory grief in program evaluations for support groups for people with terminal cancer can improve the quality of care these people receive.

In turn, studies on the role of preparatory grief in the dying process for people with terminal cancer will eventually lead to a higher quality of end-of-life care for all. The knowledge gained from the study of preparatory grief can be broadly applied. Dying, regardless of the circumstances, tends to be a distressing 
experience not only for the person who is dying but for their loved ones and their loved ones' loved ones, and so on. Thus the benefits of studying preparatory grief has a rippling effect, carrying the potential to improve countless lives, and deaths. In the words of the Greek philosopher Socrates, true wisdom is nothing but preparation for death. 


\section{References}

American Cancer Society. (2012). Cancer Facts \& Figures. Retrieved from http://pressroom.cancer.org/download/2012+Cancer+Facts+\%26+Figures.pdf

Beauchamp, T. L., \& Veatch, R. M. (1996). Ethical issues in death and dying (2nd ed.). Upper Saddle River, NJ: Prentice-Hall, Inc.

Boyes, A., Girgis, A., \& Lecathelinais, C. (2009). Brief assessment of adult cancer patients' perceived needs: development and validation of the 34-item Supportive Care Needs Survey (SCNS-SF34). Journal of Evaluation in Clinical Practice, 15, $602-606$.

Breitbart, W. (2002). Spirituality and meaning in supportive care: spirituality- and meaning-centered group psychotherapy interventions in advanced cancer. Supportive Care in Cancer : Official Journal of the Multinational Association of Supportive Care in Cancer, 10(4), 272-80.

Classen, C., Butler, L. D., Koopman, C., Miller, E., DiMiceli, S., Giese-Davis, J., ... Spiegel, D. (2001). Supportive-expressive group therapy and distress in patients with metastatic breast cancer: a randomized clinical intervention trial. Archives of general psychiatry, 58, 494-501.

Crandall, L., \& White, D. (2007). Initiating person-centered care practices in longterm care facilities. Journal of Gerontological Nursing. Retrieved from http://europepmc.org/abstract/MED/18019118

Crawford, M. (2012). Transformations: women, gender \& psychology (2nd ed.). New York: McGraw-Hill. 
DeSpelder, L. A., \& Strickland, A. L. (1987). The last dance (2nd ed.). Palo Alto, CA: Mayfield Publishing Company.

Ekman, I., Swedberg, K., Taft, C., Lindseth, A., Norberg, A., Brink, E., ... Sunnerhagen, K. S. (2011). Person-centered care--ready for prime time. European Journal of Cardiovascular Nursing : Journal of the Working Group on Cardiovascular Nursing of the European Society of Cardiology, 10(4), 248-51.

Evans, A. J. (1994). Anticipatory grief: a theoretical challenge. Palliative Medicine, 8, $159-165$.

Fitz-Gibbon, C. T., \& Morris, L. L. (1987). How to Design a Program Evaluation. Los Angelos: The Regents of the University of California.

Flanagan-Kamisky, D. (2013). Intentional anticipatory mourning, caregiver and bereveament support program for terminally ill veterans, their families and caregivers in the VA contract home hospice program. OMEGA, 67, 68-77.

Gomes, B., \& Higginson, I. J. (2008). Where people die (1974-2030): past trends future projections and implications for care. Palliative Medicine, 22(1), 33-41.

Howarth, M., Warne, T., \& Haigh, C. (2014). Pain from the inside: understanding the theoretical underpinning of person-centered care delivered by pain teams. Pain Management Nursing : Official Journal of the American Society of Pain Management Nurses, 15(1), 340-8.

Koenig, B. A., Back, A. L., \& Crawley, L. M. (2003). Qualitative methods in end-of-life research: recommendations to enhance the protection of human subjects. Journal of Pain and Symptom Management, 25, S43-S52. 
Lam, W. W., Tsang, J., Yeo, W., Suen, J., Ho, W. M., Yau, T. K., ... Fielding, R. (2013). The evolution of supportive care needs trajectories in women with advanced breast cancer during the 12 months following diagnosis. Supportive Care in Cancer, 22, 635-644.

Lindemann, E. (1944). Symptomatology and management of acute grief. American Journal of Psychiatry. Retrieved from http://www.nyu.edu/classes/gmoran/LINDEMANN.pdf

Lynn, J. (1983). The determination of death. Annals of Internal Medicine, 99(2), 264266.

Lynn, J. (2005). Living long in fragile health: The new demographics shape end-oflife care. Hastings Center Report, 35(6), S14-S18.

Maddux, J. E. (2008). Positive Psychology and the Illness Ideology: Toward a Positive Clinical Psychology. Applied Psychology: An International Review, 57, 54-70.

Morgan, S., \& Yoder, L. H. (2012). A Concept Analysis of Person-Centered Care. Journal of Holistic Nursing, 30(6), 6-15.

Murray, C., \& Wright, J. (2014). Coping with Loss : The Dying Adult. British Medical Journal, 316(7140), 1313-1315.

Mystakidou, K., Tsilika, E., Parpa, E., Katsouda, E., Sakkas, P., \& Soldatos, C. (2005). Life before death: identifying preparatory grief through the development of a new measurement in advanced cancer patients (PGAC). Supportive Care in Cancer : Official Journal of the Multinational Association of Supportive Care in Cancer, 13, 834-841. 
Mystakidou, K., Parpa, E., Katsouda, E., Galanos, A., \& Vlahos, L. (2006). The role of physical and psychological symptoms in desire for death: a study of terminally ill cancer patients. Psycho-Oncology, 15, 355-360.

Mystakidou, K., Parpa, E., Tsilika, E., Athanasouli, P., Pathiaki, M., Galanos, A., ... Vlahos, L. (2008). Preparatory grief, psychological distress and hopelessness in advanced cancer patients. European Journal of Cancer Care, 17, 145-151.

Nordin, K., Berglund, G., Glimelius, B., \& Sjödén, P. O. (2001). Predicting anxiety and depression among cancer patients: a clinical model. European Journal of Cancer 37(3), 376-84. Retrieved from http://www.ncbi.nlm.nih.gov/pubmed/11239760

The Numbers Count: Mental Disorders in America. (n.d.). NIMH RSS. Retrieved April 15, 2014, from http://www.nimh.nih.gov/health/publications/the-numberscount-mental-disorders-in-america/index.shtml

Pellegrino, E. D. (1970). Book Review: On Death and Dying. What the Dying Have to Teach Doctors, Nurses, Clergy and Their Own Families. Elisabeth Kubler-Ross. The Quarterly Review of Biology. 225.

Periyakoil, V. S., \& Hallenbeck, J. (2002). Identifying and managing preparatory grief and depression at the end-of-life. American Family Physician, 65, 883-890.

Presberg, B. A., \& Kibel, H. D. (1994). Confronting death: Group psychotherapy with terminally ill individuals. Group, 18(1), 19-28.

Riley, J. W. (1983). Dying and the Meanings of Death: Sociological Inquiries. Annual Review of Sociology, 9, 191-216. 
Schultz, R. (1978). The Psychology of death, dying, and bereavement. Addison-Wesley Publishing Company, Inc.

Spiegel, D. (1995). Essentials of psychotherapeutic intervention for cancer patients. Supportive Care in Cancer : Official Journal of the Multinational Association of Supportive Care in Cancer, 3, 252-256.

Spiegel, D., \& Yalom, I. (1978). A Support Group for Dying Patients. International Journal of Group Psychotherapy, 28(2), 233-245. Retrieved from http://psycnet.apa.org/psycinfo/1980-21610-001

Stephenson, J. S. (1985). Death, grief, and mourning. New York, NY: The Free Press.

Tsilika, E., Mystakidou, K., Parpa, E., Galanos, A., Sakkas, P., \& Vlahos, L. (2009). The influence of cancer impact on patients' preparatory grief. Psychology \& Health, $24,135-148$.

Vromans, L., Schweitzer, R. D., \& Brough, M. K. (2012). Demographic and clinical predictors of preparatory grief in a sample of advanced cancer patients. Journal of Nervous and Mental Disease, 200(4), 349-357. 


\title{
Appendices
}

\author{
Appendix A: Informed consent form \\ Informed Consent Form
}

May 13, 2014

Dear Participant,

I am Ariel Young, working for the XXXXX organization. I am asking you to participate in a study on preparatory grief, the process of grieving your own death before it happens, in people with advanced cancer. I am going to give you information about this research and invite you to be part of it. Your response is important because I need information only you, a person diagnosed with advanced cancer, can provide. You do not have to decide today whether or not you will participate in the research. Before you decide, you can talk to anyone you feel comfortable with about the research and this form. If you have questions now or later, you are free to ask them of me or another researcher on our team.

What is the purpose of this research? Preparatory grief is a normal response to extraordinary circumstances and it is not completely understood. The purpose of this study is to measure how support groups for people with terminal cancer effects preparatory grief. We believe you can help by telling us about yourself. We want to learn more about preparatory grief, who experiences it, how and when it is experienced, and whether or not support groups are helpful. 
Why have you been asked to participate? You are being asked to participate in this research because your hospital reported that you were diagnosed with advanced cancer. Your experience is valuable to us and can contribute to our understanding of preparatory grief.

Do you have to participate? You decision to be a part of this research is entirely up to you. You may decide whether or not you would like to be a part of this research. Should you choose not to participate, your relationship with your doctors and hospital will not change. If you do choose to participate, you may stop participating at any time without consequence. You will also have a chance to review your survey and you may change your answers before it is submitted.

What will the research be like? This research will involve a series of surveys, which should take no more than 20 minutes to complete. If you choose to participate, you will also be asked to choose a proxy, or a person who has your permission to fill out the surveys for you should you be unable to complete the surveys yourself. Should you choose to be a part of this research, you will be asked to fill out surveys which will be provided and collected by the XXXXX organization. You may answer the survey yourself, or it can be read to you and you can say out loud the answer you want the researcher to write down. If you do not wish to answer any of the questions included in the survey, you may skip them and move on to the next question. The information recorded is private, your name or any other identifying pieces of information are not being included on the forms, only a number will 
identify you, and no one else except myself and the other researchers on my team will have access to your survey.

The initial survey will be given to you after you have signed this consent form. Another survey will be given to you in 10 weeks. If you are unable to fill out the second survey yourself, your proxy will be asked to fill out the survey for you. What are the risks of participating? There is a chance that you may feel uncomfortable answering the survey questions. However, we do not want that to happen. If you do not wish to answer a question for any reason, you may skip it and move on to the next question.

What are the benefits of participating? There will be no direct benefit to you as a result of this survey. However, we hope that the information you provide us will help us better understand preparatory grief, and make social support more helpful for other people who have been diagnosed with terminal cancer.

How will your information be kept private? We will not be sharing any information which could identify you with anyone outside of the research team. Any information collected will have an ID number instead of your name. Only the researchers will have access to your identification number.

Will you get to see the results of the study? Each participant will receive a summary of the results of this study. We hope to publish our results in order to make our research available to the public. Remember, we will not share any information which can identify you with anyone outside of the research team. 
What if you have a question? If you have any questions, you can ask them now or later. If you wish to ask questions later, you may contact the research team. This proposal has been reviewed and approved by [name of the local IRB], which is a group of people whose job it is to make sure that you are protected from harm. If you wish to find about more about the IRB, contact $\mathrm{XXXXXX)}$

Signed:

Signed:

(Name, Participant)

(Name, Reseacher)

(Print name) 
Appendix B: Initial intake survey

Initial Intake Survey

\section{Participant ID number:}

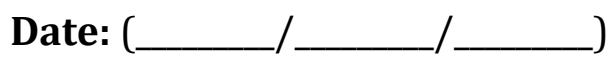

\section{Please provide us with your contact information}

Phone number: (____________

Email:

Mailing address:

Date of birth: /________

Please select one answer to each of the following questions.

1. What is your gender?

1 Man ${ }^{2}$ Woman $^{3}$ Other

2. What is your race?

1 White ${ }^{2}$ Black or African American ${ }^{3}$ American Indian or Alaskan Native 4 Asian ${ }^{5}$ Native Hawaiian or Other Pacific Islander

6 Two or more races (please specify)

\section{Are you of Hispanic origin?}

1 Yes, I am Hispanic ${ }^{2}$ No, I am not Hispanic 
4. What is the highest level of education you have completed?

1 Junior high or less ${ }^{2}$ High school $^{3}$ Some college

4 Associate's degree ${ }^{5}$ Bachelor's degree ${ }^{6}$ Master's degree

7 Doctorate and above

5. What is your marital status?

1 Single ${ }^{2}$ Partnered or Married ${ }^{3}$ Divorced ${ }^{4}$ Widowed

6. What is your total household income:

1 Less than $\$ 10,000^{2}$ Between $\$ 10,000$ and $\$ 30,000$

3 More than $\$ 30,000$

7. How many people are in your household, including yourself?

$1 \quad 1$ person $^{2} 2$ people $^{3} \quad 3$ people $4 \quad 4$ people

5 people 6 or more people

8. Have you ever been diagnosed with a psychological disorder by a doctor, or licensed counselor or therapist?

1 Yes $^{2}$ No $^{3}$ I don't know

9. When we you diagnosed with a psychological disorder?

1 Please specify _____ I don't know

10. What psychological disorder were you diagnosed with?

1 Please specify _____ I don't know

11. What kind of cancer have you been diagnosed with?

1 Breast $^{2}$ Colorectal $^{3}$ Prostate $^{4}$ Lung $^{5}$ Other 
12. When were you first diagnosed with cancer?

1 Please specify ______ I don't know

13. When did you learn your cancer was terminal?

1 Please specify ___ ${ }^{2}$ I don't know

14. What treatments have you undergone for your cancer? This question may have multiple answers, check all that apply.

1 None $^{2}$ Radiation therapy ${ }^{3}$ Chemotherapy ${ }^{4}$ Surgery $^{5}$ Opioids

6 Alternative medicine ${ }^{7}$ Other

15. Are you involved in a support group for people with terminal cancer?

1 Yes $^{2}$ No

16. Are you interested in a support group?

1 Yes $^{2}$ No

17. If you are not interested in a support group, are you receiving social support elsewhere?

1 Yes $^{2}$ No

18. If you are receiving social support outside of a support group for people with terminal cancer, what kind of support is it?

1 Individual counseling or psychotherapy ${ }^{2}$ Group counseling or psychotherapy ${ }^{3}$ Religious guidance or counseling 4 Community group

5 Family and friends 6 Other 
In the event that you are unable to complete a follow up survey, please name a proxy:

Proxy name:

Relationship to proxy:

Please provide us with your proxy's contact information:

Proxy phone number: (______-_________

Proxy email:

Proxy mailing address:

Thank you for your valuable time. 
Appendix C: Preparatory Grief in Advanced Cancer (PGAC) patients scale Preparatory Grief in Advanced Cancer (PGAC) patients scale

Developed by Mystakidou et. al (2005), originally published in Supportive care in cancer: official journal of the Multinational Association of Supportive Care in Cancer

A number of statements are given below that describe people's reactions to having cancer. Please write the appropriate number on the line to the right of each statement, indicating how much you agree or disagree at present. For example, if the statement "disagree" apply to you then you should write number 0 on the line.

Remember there are no right or wrong answers. Answers: Disagree=0, Disagree a little=1, Agree a little=2, Agree=3.

1. I have lost my interest in family and friends.

2. I have lost my interest in activities which I was pleased to be involved with.

3. I have difficulties in falling asleep because I am thinking of my Illness.

4. I cry all the time.

5. I cannot accept my illness.

6. I cannot accept the possibility of death.

7. I feel often that what is happening to me is unfair.

8. I feel very sad.

9. I feel that I have not adjusted to my illness.

10. I feel alone.

11. I am extremely afraid of the unknown.

12. I feel angry about what has happened to me.

13. I am afraid of being abandoned by my family.

14. I pray to God more than usual.

15. I believe what is happening to me is God's will.

16. I believe that I will overcome my health problem.

17. I believe that I am a burden to my family and it would be better if I died.

18. I feel that I am still a useful and necessary person.

19. I feel upset.

20. I feel anger. 
21. I feel that I have unfulfilled wishes.

22. I feel that I have unfinished business that I have to take care of.

23. I feel that death would be a release.

24 . I cannot recognize my body anymore.

25. I believe in life after death.

26. I am afraid that I have lost my dignity.

27. I feel I have lost my independence.

28. I would like to live up to 100 years old.

29. Recently I have often had a high pulse rate.

30. I am not interested in anything any more.

31. I have lost my faith in God.

Thank you very much for your cooperation. 
Appendix D: Follow-up survey

Follow-up survey

Participant ID number:

Date:

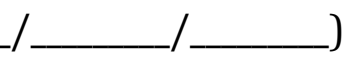

Please select one answer to each of the following questions.

1. Are you filling out this survey for yourself, or someone else?

1 Myself 2 Someone else

If you are filling out this survey for someone else, please

respond to the following questions with the answers you believe

the person you are filling out this form for would choose.

2. What is your marital status?

1 Single $^{2}$ Partnered or Married ${ }^{3}$ Divorced ${ }^{4}$ Widowed

3. What is your total household income:

1 Less than $\$ 10,000^{2}$ Between $\$ 10,000$ and $\$ 30,000$

3 More than $\$ 30,000$

3. How many people are in your household, including yourself?

$1 \quad 1$ person $^{2} 2$ people $^{3} \quad 3$ people $4 \quad 4$ people

$5 \quad 5$ people $6 \quad 6$ or more people

4. Have you ever been diagnosed with a psychological disorder by a doctor, or licensed counselor or therapist?

1 Yes $^{2} \mathrm{No}^{3}$ I don't know 
5. When we you diagnosed with a psychological disorder?

1 Please specify ___ ${ }^{2}$ I don't know

6. What psychological disorder were you diagnosed with?

1 Please specify ___ ${ }^{2}$ I don't know

7. What treatments have you undergone for your cancer? This question may have multiple answers, check all that apply.

1 None $^{2}$ Radiation therapy ${ }^{3}$ Chemotherapy ${ }^{4}$ Surgery ${ }^{5}$ Opioids

6 Alternative medicine ${ }^{7}$ Other

8. Are you involved in a support group for people with terminal cancer?

1 Yes $^{2}$ No

9. If you are not in a support group for people with terminal cancer, are you receiving social support elsewhere?

1 Yes $^{2}$ No

10. If you are receiving social support outside of a support group for people with terminal cancer, what kind of support is it?

1 Individual counseling or psychotherapy ${ }^{2}$ Group counseling or psychotherapy $^{3}$ Religious guidance or counseling ${ }^{4}$ Community group

5 Family and friends 6 Other

Thank you for your valuable time. 